P0175

\title{
EFFECTIVE LIGHTING FACTORS FOR IMPROVING VISIBILITY OF FALLEN OBJECTS ON THE ROAD IN EXPRESSWAY TUNNELS \\ Yoshihisa Ikeda et al.
}

DOI 10.25039/x46.2019.PO175

from

CIE x046:2019

Proceedings

of the

29th CIE SESSION

Washington D.C., USA, June 14 - 22, 2019

(DOI 10.25039/x46.2019)

The paper has been presented at the 29th CIE Session, Washington D.C., USA, June 14-22, 2019. It has not been peer-reviewed by CIE.

(c) CIE 2019

All rights reserved. Unless otherwise specified, no part of this publication may be reproduced or utilized in any form or by any means, electronic or mechanical, including photocopying and microfilm, without permission in writing from CIE Central Bureau at the address below. Any mention of organizations or products does not imply endorsement by the CIE.

This paper is made available open access for individual use. However, in all other cases all rights are reserved unless explicit permission is sought from and given by the $\mathrm{CIE}$.

CIE Central Bureau

Babenbergerstrasse 9

A-1010 Vienna

Austria

Tel.: +4317143187

e-mail: ciecb@cie.co.at

www.cie.co.at 


\title{
EFFECTIVE LIGHTING FACTORS FOR IMPROVING VISIBILITY OF FALLEN OBJECTS ON THE ROAD IN EXPRESSWAY TUNNELS
}

\author{
Ikeda, Y. ${ }^{1}$, Okusa, K. ${ }^{1}$, Utsunomiya, $\mathrm{S} .{ }^{1}$, Miyake, $\mathrm{K}^{2}{ }^{2}$ Jinno, M. ${ }^{1}$ \\ ${ }^{1}$ Ehime University, Matsuyama, JAPAN, ${ }^{2}$ West Nippon Expressway Engineering Shikoku \\ Company Limited, Takamatsu, JAPAN \\ mjin@mayu.ee.ehime-u.ac.jp
}

DOI 10.25039/x46.2019.PO175

\begin{abstract}
Securing the driver's visual environment is a priority of tunnel lighting design. Safety in the visual environment of the tunnel is determined predominantly by the visibilities of the preceding vehicles and any on-road obstacles. This study verifies that pro-beam lighting improves the visibility in an expressway tunnel. The authors investigated the necessary luminance ratio of objects to background road surface, at which drivers can recognize objects in a tunnel. The authors also investigated other lighting factors (such as equivalent veiling luminance and horizontal and vertical illuminance) and their relationship to visibility. On asphalt and concrete roads with the same background illuminance, the silhouette view was more visible than the reverse silhouette view. The visibility of both silhouette and reverse silhouette views increased with horizontal illuminance on the asphalt road. In the multiple regression analysis, the main factors for improving visibility in the tunnel were the luminance ratio.
\end{abstract}

Keywords: Tunnel lighting, Visibility, Expressway, Luminance ratio, Pro-beam

\section{Introduction}

Approximately $50 \%$ of the cargo flow in Japan (which exceeds 2.5 billion ton/year) is transported by vehicles (MLIT. 2015; MLIT Basic Policy Subcommittee. 2017). Expressways constitute less than $1 \%$ of all roads in total length, but carry $47.7 \%$ of the domestic land freight (Highway Maintenance Network. 2012). In other words, expressways support Japanese logistics. The greatest risk on expressways is traffic accidents in tunnels. Japan's expressways pass through many tunnels hollowed through the mountainous terrain. In fact, there are 1076 tunnels along the expressways in Japan (MLIT. 2017). Traffic accidents in tunnels are usually slow to clear and there are few alternative routes. The long-time shut down of the logistics, causing blockage of the transportation, largely impacts on Japan's economy. Therefore, a driving environment that suppresses the occurrence of accidents is strongly desired.

According to a survey of the Tokyo Metropolitan Expressway Bayshore Route, the accident rate in tunnel sections is approximately 103 cases per 100 million vehicle kilometers, 1.1 times higher than in other sections (Goto et al., 2005). Moreover, the mortality rate is usually higher in expressway accidents than in accidents on general roads (Matsubara, 1984). These results highlight the importance of visibility in accident-avoidance. Therefore, we have been developing a new lighting method that improves the visibility in road tunnels.

To ensure safe visual environments, improving the visibility of obstacles and other vehicles on roads is vital. Conventional (fixed) road lighting provides a silhouette view (Figure 1) against a bright road-surface background. More recently, pro-beam luminaires have provided reverse silhouette views of bright objects against the dark road surface. Kimura et al. (2019) verified that improving the vertical illuminance using a pro-beam improves the view of the trailing vehicles. Several measures for quantifying visibility have been proposed. Narisada et al. (1997) reported the total revealing power as an indicator of threshold visibility. The so-called visibility level (VL) reported by Janoff (1990) indicates the excess visibility (visibility above the threshold visibility) of an object of defined size, shape, and reflectance. The small-target visibility is the VL calculated under strict conditions defined by the Illuminating Engineering 
Society of North America (ANSI/IESNA 2000, 2014). However, these measures are calculated by complicated equations, and sometimes require many measurement items. Also, the result of the equations can mismatch the evaluation by the subject, leaving an ambiguous constant called the field factor.

Recently, several studies have improved the visibility in tunnels using light-emitting diode (LED) luminaires (Kimura et al., 2014, 2019; Hirakawa et al., 2014, 2015). LEDs provide more freedom in the lighting design than conventional light sources. Miyake et al. (2019) combined a pro-beam with color control or pulse control to improve the visibility in a tunnel. However, the mechanism by which lighting improves the visibility in tunnels has not been clarified yet.

In the present study, the authors verify the visibility improvement effect of pro-beam lighting. The necessary luminance ratio of objects to the background road surface, at which drivers can recognize the objects in a tunnel, is investigated. The study also relates the visibility to other optical parameters (such as the horizontal and vertical illuminances of the road surface and the equivalent veiling luminance). The measured values and visibility are input to a multiple regression analysis as the explanatory variables and criterion variable, respectively. The multiple regression analysis returns a simple visibility expression. Finally, the main factors determining visibility are identified and the visibility mechanism is clarified.

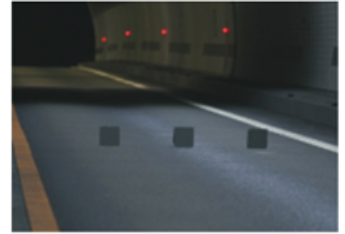

Silhouette view

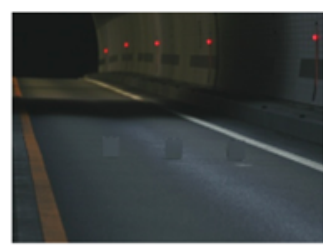

Reverse silhouette view

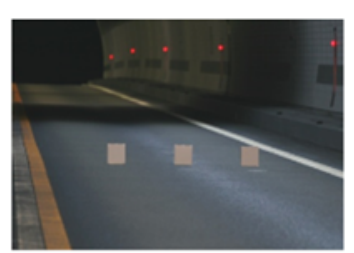
Low

Reflectivity of the objects

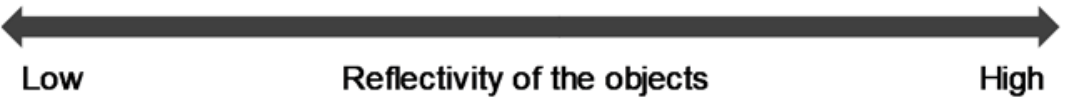

Figure 1 - Relationship between negative and positive contrast viewing and visibility.

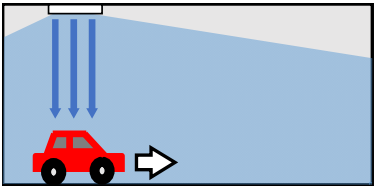

Symmetric-beam

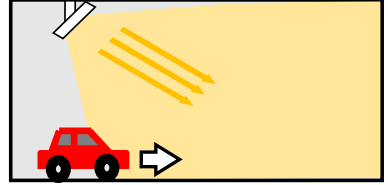

Pro-beam

Figure 2 - Schematic showing two different lighting methods in a tunnel.

\section{Experimental setup}

The authors prepared a 1/24-scale model of an expressway tunnel containing two types of roads: one painted to resemble concrete, the other painted to resemble asphalt. The reflectivities of the concrete-like and asphalt-like road surfaces were $10 \%$ and $80 \%$, respectively. The tunnel model also contained pro-beam and symmetric light-distribution LEDs. The color temperature of the LEDs (NVSW119BT; Nichia, Tokushima, Japan) was $5500 \mathrm{~K}$. The model tunnel is schematized in Figure 3. The positions of the luminaires, object, and luminance measurements of the road and object surfaces are presented in Figure 4 . The object was sized $8.3 \mathrm{~mm} \times 8.3 \mathrm{~mm}$ (length $\times$ width), and its reflectivity was varied as $9 \%, 25 \%$, $56 \%, 69 \%, 77 \%$, and $90 \%$. The average road surface luminance around the object was set to 4,13 , or $20 \mathrm{~cd} / \mathrm{m}^{2}$. The average road illumination of $4.5 \mathrm{~cd} / \mathrm{m}^{2}$ is generally used based on the road lighting standards and guidelines in Japan (JARA, 2007). The distribution angle of the pro-beam was set to $45^{\circ}, 60^{\circ}, 70^{\circ}$ or $80^{\circ}$. The effect of visibility on the road-surface luminance was determined by changing the input power and the pro-beam to symmetric-beam ratio. The horizontal and vertical illuminances, luminance of the fallen object, luminance of the road surface, and the equivalent veiling luminance under each condition were measured by a 
spectroradiometer (SR-3; Topcon, Tokyo, Japan) and a Chroma meter (CL-200; Konica Minolta, Tokyo, Japan).

In a survey, the test subjects evaluated the visibility of the object placed on the road at $4.17 \mathrm{~m}$ from their eyes in the model tunnel. This distance corresponds to $100 \mathrm{~m}$ on $1 / 1$ scale. The test subjects were nine students enrolled at Ehime University (Ehime, Japan). The visibility scale ranged from 1 (none) to 5 (high), as shown in Table 1.

To evaluate how the optical factors of the tunnel lighting (which construct the visual environment of the tunnel) affected the visibility, a multiple regression analysis was performed with the criterion variable as an average visibility score and the explanatory variable as an optical parameter. The average visibility score was determined in four cases: silhouette view/asphalt road, reverse silhouette view/ asphalt road, silhouette view/concrete road, and reverse silhouette view/concrete road. The horizontal illuminance, vertical illuminance, luminance of fallen object, luminance of road surface, and equivalent veiling luminance were the explanatory variables.

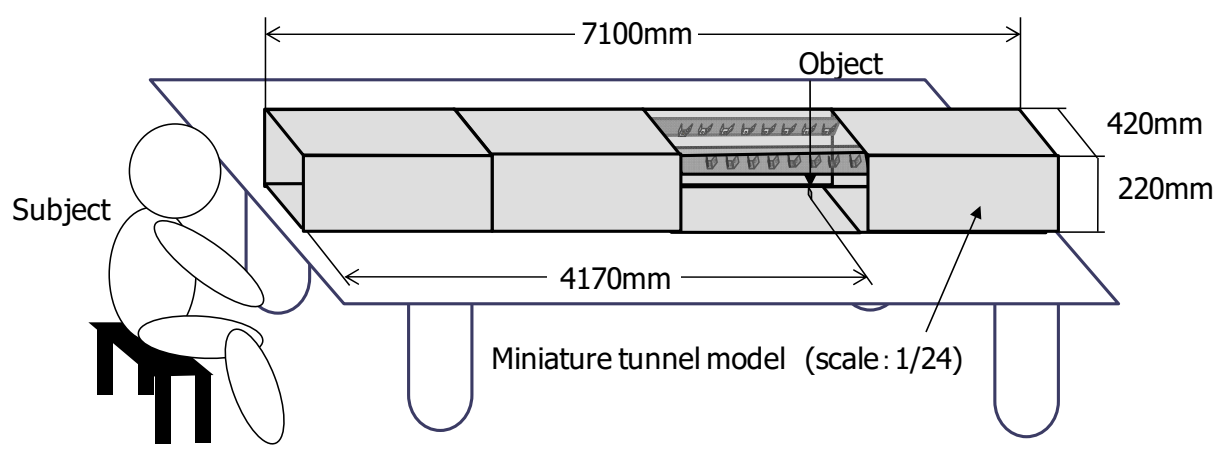

Figure 3 - Schematic of the visibility evaluation in a $1 / 24$-scale tunnel model.
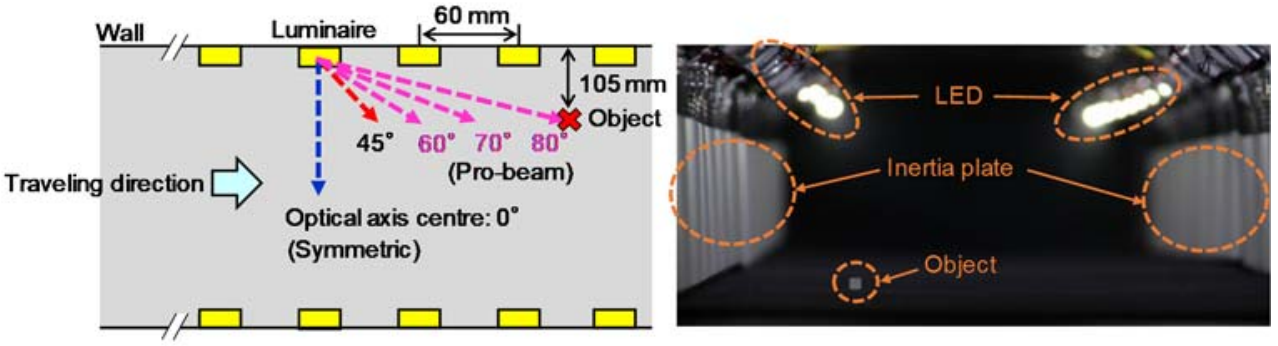

Figure 4 - Positions of the luminaires, object, and luminance measurements on the road surface and object.

Table 1 - Visibility scale

\begin{tabular}{|c|c|c|c|c|c|}
\hline Point & 0 & 1 & 2 & 3 & 4 \\
\hline Visibility & None & $\begin{array}{c}\text { Slightly } \\
\text { Visible }\end{array}$ & Visible & $\begin{array}{c}\text { Slightly } \\
\text { High }\end{array}$ & High \\
\hline
\end{tabular}

\section{Luminance ratio (road surface: fallen object) dependence on visibility}

Figure 5 shows photographs of the fallen object on the asphalt and concrete surfaces. The average road surface luminance was $13 \mathrm{~cd} / \mathrm{m}^{2}$. When the luminance ratio was below and above 1.0, the object was visible in silhouette view and reverse silhouette view, respectively. The visibility differed on the asphalt and concrete, even when both roads received the same surface luminance. For example, when the luminance ratio was 1.07 , the average visibility score was 0.77 on asphalt and 0.10 on concrete (Figure 5). 
Figure 6 shows the luminance ratio dependences on the average visibility scores given in the survey. In each plot and in both views (silhouette and reverse silhouette), the visibility was a linear function of the luminance ratio. When the average score was 1 or less, the slopes were larger for the concrete surface than the asphalt surface, reflecting the higher visibility on the concrete road than the asphalt road at the same luminance ratio. In silhouette and reverse silhouette viewing, the luminance ratio at which the object could be recognized (average score 1.0) increased and decreased respectively with increasing road-surface luminance. This trend appeared on both road surfaces. This result shows that the discrimination threshold of the luminance ratio, at which an object can be recognized on the background surface, depends not only on the road-surface luminance but also on the view (silhouette or reverse silhouette).

The next section presents the multiple regression analysis (omitting the combination of explanatory variables with likely multicollinearity), and calculates the variance inflation factor.

\begin{tabular}{|c|rr|rr|rr|}
\hline Reflectivity & \multicolumn{2}{|c|}{$\begin{array}{c}\text { Symmetric } \mathbf{1 0 0} \% \\
\text { Pro-beam 0 \% }\end{array}$} & $\begin{array}{c}\text { Symmetric 75 \% } \\
\text { Pro-beam 25 \% }\end{array}$ & $\begin{array}{c}\text { Symmetric 50 \% } \\
\text { Pro-beam50 \% }\end{array}$ \\
\hline $\mathbf{2 5 \%}$ & Points & Ratio & & & \\
& 0.3 & 1.07 & 1.4 & 1.49 & 2.3 & 1.91 \\
\hline $\mathbf{9} \%$ & & & & & & \\
& 1.8 & 0.55 & 1.7 & 0.77 & 0.4 & 1.00 \\
\hline
\end{tabular}

(a) Asphalt road

\begin{tabular}{|c|rr|rr|cr|}
\hline Reflectivity & $\begin{array}{c}\text { Symmetric } \mathbf{5 0} \% \\
\text { Pro-beam } \mathbf{5 0} \%\end{array}$ & $\begin{array}{c}\text { Symmetric } \mathbf{2 5} \% \\
\text { Pro-beam } \mathbf{7 5} \%\end{array}$ & $\begin{array}{c}\text { Symmetric 0 \% } \\
\text { Pro-beam 100 \% }\end{array}$ \\
\hline $\mathbf{9 0} \%$ & 0.4 & 1.26 & 1.2 & 1.39 & 1.7 & 1.49 \\
\hline $\mathbf{7 7} \%$ & & & & & & \\
& 0.2 & 0.96 & 0.1 & 1.07 & 0.1 & 1.15 \\
\hline
\end{tabular}

(b) Concrete road

Figure 5 - Photographs of a fallen object on the asphalt and concrete surfaces in the simulated road tunnel.

The luminance ratio is the object luminance divided by the road surface luminance. (Average road surface luminance $=13 \mathrm{~cd} / \mathrm{m}^{2}$ ). 


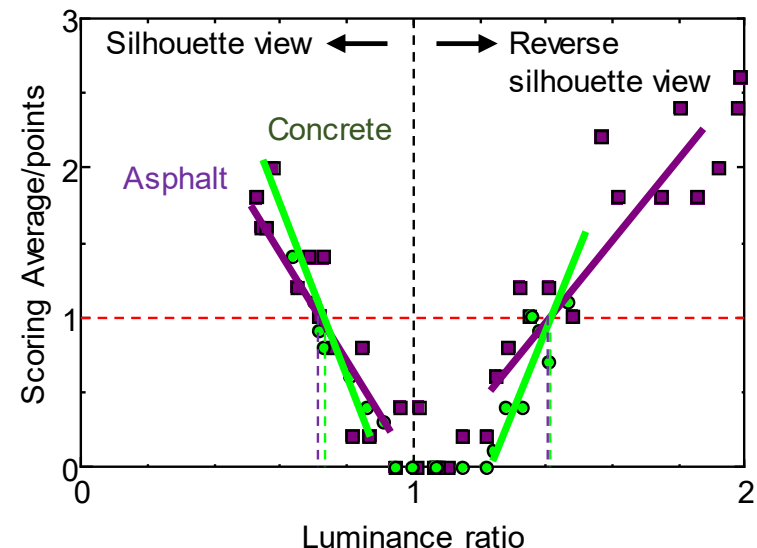

(a) Road surface luminance: $4 \mathrm{~cd} / \mathrm{m}^{2}$

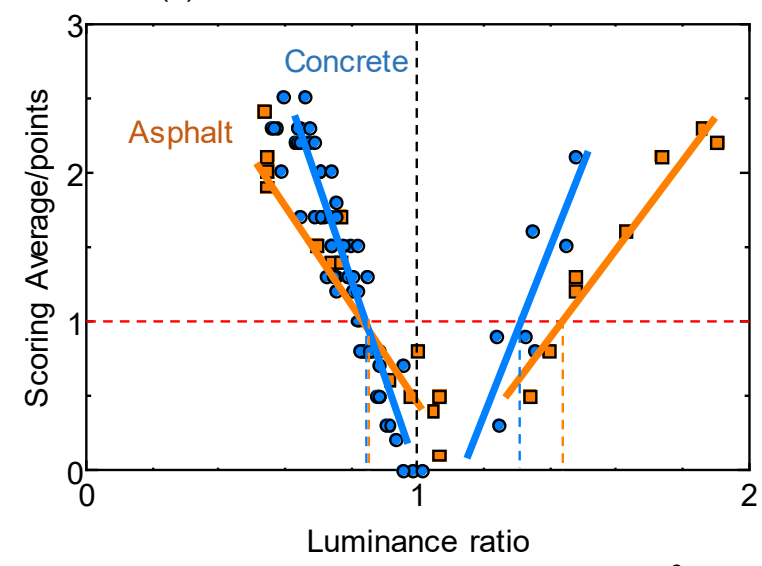

(c) Road surface luminance: $20 \mathrm{~cd} / \mathrm{m}^{2}$

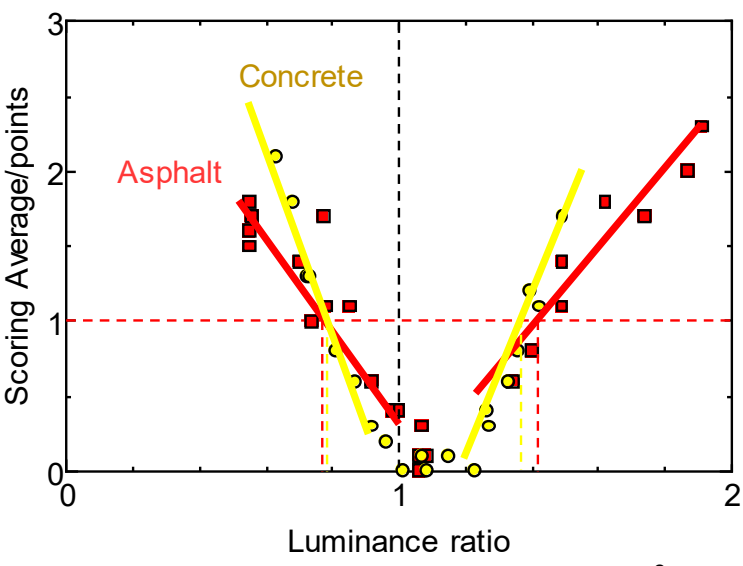

(b) Road surface luminance: $13 \mathrm{~cd} / \mathrm{m}^{2}$

Figure 6 - Relationships between visibility (average score of nine subjects) and luminance ratio under different road-surface illuminations.

Table 2 - Results of the multiple regression analysis. (*p <0.05)

\begin{tabular}{|c|c|c|c|c|}
\hline & \multicolumn{2}{|c|}{ Partial regression coefficient } & \multirow{2}{*}{$\begin{array}{c}\text { Constant: } \\
\text { C }\end{array}$} & \multirow[b]{2}{*}{$R^{2}$} \\
\hline & $\begin{array}{l}\text { 1-Luminance } \\
\text { ratio: } K_{1}\end{array}$ & $\begin{array}{c}\text { Horizontal } \\
\text { illuminance: } K_{2}\end{array}$ & & \\
\hline $\begin{array}{l}\text { Silhouette view, } \\
\text { Asphalt road }\end{array}$ & $3.52^{*}$ & $1.18 \times 10^{-3 *}$ & $0.02^{*}$ & 0.83 \\
\hline $\begin{array}{l}\text { Reverse silhouette view, } \\
\text { Asphalt road }\end{array}$ & $-2.48^{*}$ & $1.77 \times 10^{-4}$ & $0.01^{*}$ & 0.90 \\
\hline $\begin{array}{l}\text { Silhouette view, } \\
\text { Concrete road }\end{array}$ & $5.78^{*}$ & $1.38 \times 10^{-2 *}$ & $-0.74^{*}$ & 0.90 \\
\hline $\begin{array}{l}\text { Reverse silhouette view, } \\
\text { Concrete road }\end{array}$ & $-3.20^{*}$ & $9.28 \times 10^{-3 *}$ & $-0.61^{*}$ & 0.78 \\
\hline
\end{tabular}




\section{Identification of optical factors contributing to visibility by multiple regression analysis}

Table 2 presents the results of the multiple regression analysis. The adjusted $R$-squared value $\left(R^{2}\right)$ was maximized by combining the luminance ratio and horizontal illuminance. The regression equation is given by

Evaluation of Visibility $=K_{1} \times\left(1-R_{\mathrm{L}}\right)+K_{2} \times L_{\mathrm{H}}+C$,

where

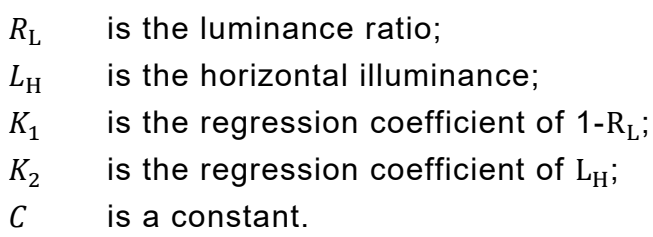

According to the above expression, the visibility is determined mainly by the luminance ratio, and also by the horizontal illuminance (independently of the luminance ratio). The horizontal illuminance makes a larger contribution in silhouette view than in reverse silhouette view, meaning that the horizontal illuminance exerts a greater influence on the visibility in silhouette viewing than in reverse silhouette viewing.

Figure 7 plots the visibility (average scores) versus the luminance ratio on the two road surfaces illuminated by different amounts. The solid line in each plot is the linear regression result. This figure shows that the visibility was higher in silhouette viewing than in reverse silhouette viewing, regardless of the road surface. Moreover, increasing the surface brightness of the asphalt road raised the y-intercept of the plot. This result highlights the influence of the horizontal illuminance in the regression equation. On the asphalt road, the visibility increased with horizontal illuminance in both silhouette and reverse silhouette viewing.

These results show that on the asphalt road, increasing the luminance ratio improved the visibility in both silhouette and reverse silhouette views. For this purpose, the pro-beam is an effective illumination source. Increasing the horizontal illumination also improved the visibility. On the concrete road, the pro-beam did not effectively increase the luminance ratio in either viewing mode, and increasing the horizontal illuminance was also less effective on this road surface.

\section{Discussion}

In the multiple regression analysis, the visibility was effectively improved by the ratio of the object luminance to the road-surface luminance, and by the horizontal illuminance. Under the influence of horizontal illumination, the $y$-intercept of the regression equation of the asphalt road was raised by increasing the road surface brightness. This indicates that the luminance difference threshold is not fixed, but depends on the ambient brightness.

In CIE 019.22-1981, the luminance difference threshold is reported to decrease with ambient brightness up to some small value, after which the luminance difference threshold remains constant and Weber's law holds (CIE019.22-1981. 1981). On asphalt roads, horizontal illuminance is required to obtain the same background luminance as concrete roads, so the viewing environment must be brighter for asphalt roads than for concrete roads with the same background luminance. Owing to the horizontal illuminance component, it is assumed that the luminance difference threshold is smaller in the asphalt case than in the concrete case.

Against the same background brightness, the silhouette view had higher visibility than the reverse silhouette view. To obtain the same visibility as the silhouette view, the reverse silhouette view requires a larger luminance ratio. The authors expect that the luminance difference thresholds differ between the two viewing modes. This phenomenon will be clarified in future study. 


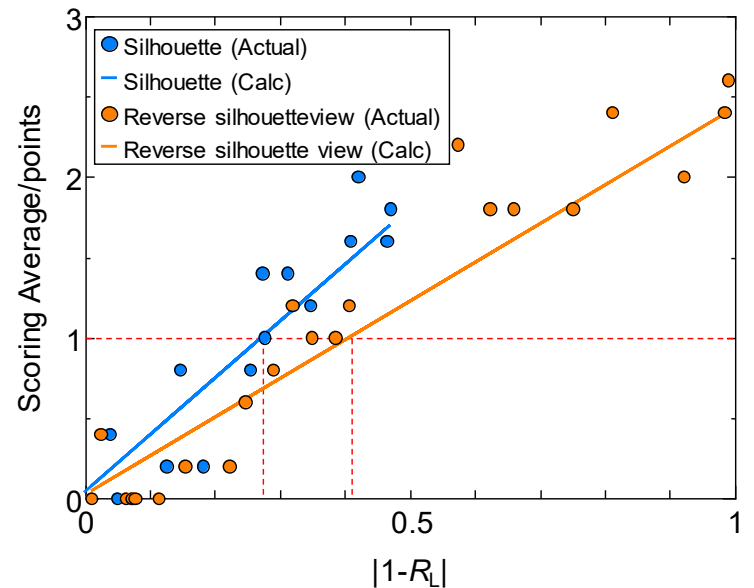

(a) Asphalt road surface luminance: $4 \mathrm{~cd} / \mathrm{m}^{2}$

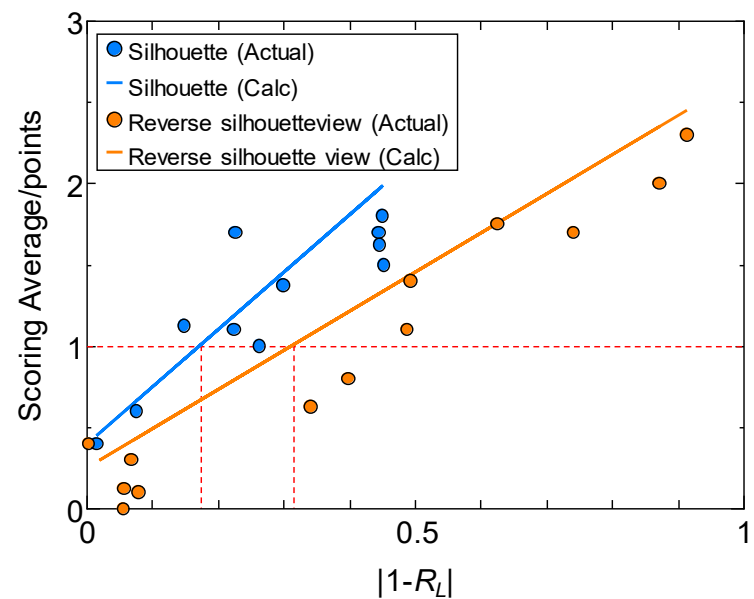

(c) Asphalt road surface luminance: $13 \mathrm{~cd} / \mathrm{m}^{2}$

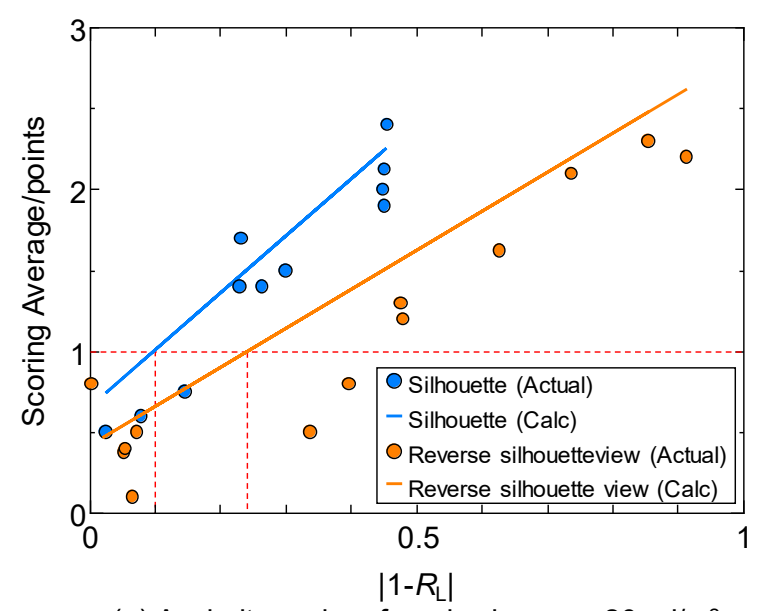

(e) Asphalt road surface luminance: $20 \mathrm{~cd} / \mathrm{m}^{2}$

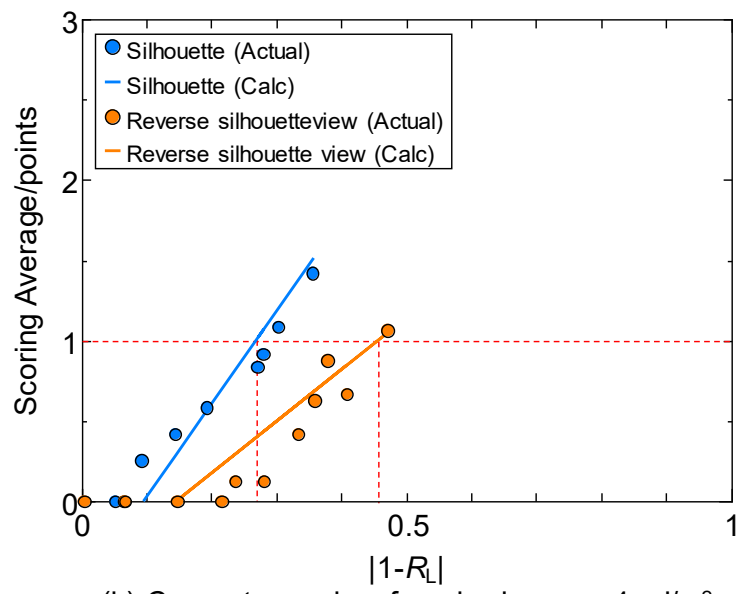

(b) Concrete road surface luminance: $4 \mathrm{~cd} / \mathrm{m}^{2}$

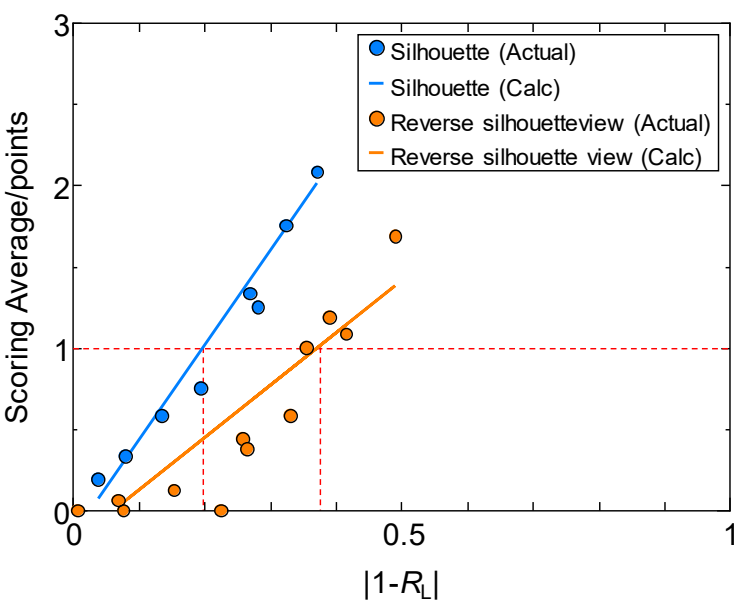

(d) Concrete road surface luminance: $13 \mathrm{~cd} / \mathrm{m}^{2}$

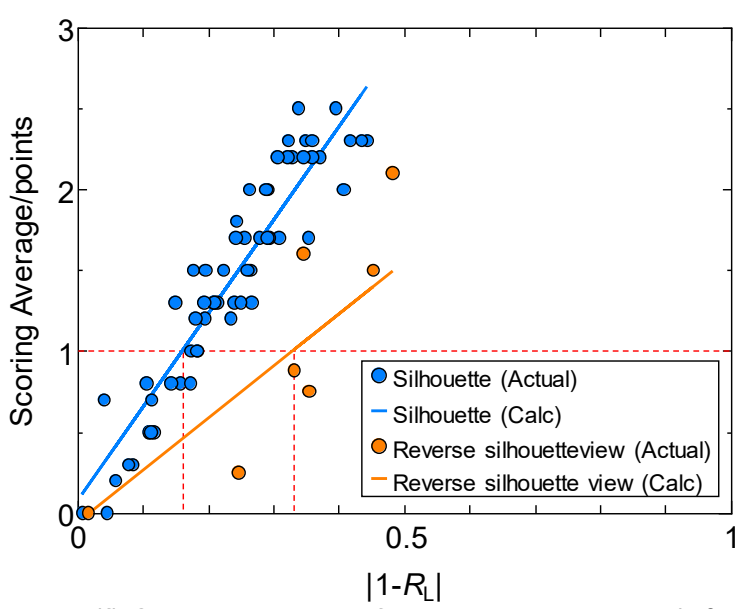

(f) Concrete road surface luminance: $20 \mathrm{~cd} / \mathrm{m}^{2}$

Figure 7 - Relationship between visibility (average score of nine subjects) and luminance ratio $R\llcorner\mathrm{~L}$ under different road-surface illuminations on asphalt (left) and concrete (right). 


\section{Conclusion}

This study verified that pro-beam lighting improves the visibility in expressway tunnels. The necessary luminance ratio of objects to the background road surface, at which drivers can recognize objects on the road, was evaluated in a 1/24-scale model of an expressway tunnel. Other optical parameters, such as the horizontal and vertical illuminances of the road surface and the equivalent veiling luminance, were also measured, and related to the visibility. The measured values and visibility scores were input to a multiple regression analysis as the explanatory variables and criterion variable, respectively.

For the same background brightness, the visibility was higher in silhouette viewing than in reverse silhouette viewing, regardless of the road surface. Furthermore, in both viewing modes, the visibility on the asphalt road (but not on the concrete road) increased with increasing horizontal illuminance. In the multiple regression analysis, the important factors for improving visibility in the tunnel were the luminance ratio between the background road surface and the object, and the horizontal illuminance in the visual environment.

\section{References}

CIE 1981. CIEPubl. No.19.21, An analytic model for describing the influence of lighting parameters upon visual performance, 2 nd ed. 1.

Goto, H., Tanaka, A., Akahane, H. and Warita, H. 2005. Proceedings of 25th Traffic Engineers, 49-52 (in Japanese).

Highway Maintenance Network. 2012. Highway Handbook 2012 (in Japanese).

Hirakawa, S., Karasawa, Y., Funaki, T. Yoshida, Y. 2014. Evaluation index of visibility in tunnel lighting, Journal of Light \& Visual Environment, 38, 117-127.

Hirakawa, S., Karasawa, Y. Funaki, T. 2015. Vis-ibility evaluation of expressway Tunnel lighting in consideration of vehicle headlights, Electrical Engineering in Japan, 193, 2, 557-564.

Janoff, MS. 1990. The effect of visibility on driver performance: a dynamic experiment. $J$ Illumin. Eng. Soc., 19, 57-63.

Japan Road Association (JARA). 2007. Road lighting standards and guidelines, 195-197.

Kimura, M., Hamada, Y., Ikeda, Y., Motomura, H., Jinno, M. 2019. Importance of a Vector Component and the Vertical Illuminance in Road Lighting for the Obstacle Visibility of the Road. Journal of Science and Technology in Lighting, 42, 17-21.

Kimura, M., Hirakawa, S., Uchino, H., Motomura, H., Jinno, M. 2014. Energy Savings in Tunnel Lighting by Improving the Road Surface Luminance Uniformity-A New Approach to Tunnel Lighting-. Journal of Light \& Visual Environment, 38, 66-78.

Matsubara, Y. 1984. Tunnels and Traffic Accidents on Expressways. IATSS Review, 10, 1, 39-45 (in Japanese).

Ministry of Land, Infrastructure, Transport and Tourism (MLIT). 2015. Survey on the Net Cargo Flow in Japan.

Ministry of Land, Infrastructure, Transport and Tourism (MLIT) Basic Policy Subcommittee. 2017. The situation surrounding distribution.

Ministry of Land, Infrastructure, Transport and Tourism (MLIT). 2017. Statistical Survey on Roads.

Miyake, K. Ota, S. Shigematsu, D. Ohkusa, K. Ikeda, Y. Jinno, M. 2019. Visibility Improvement in Expressway Tunnels by Optimizing the Color Temperature and Light Distribution of the Pulse-operated LED Luminaires. Journal of Science and Technology in Lighting, 42, 22-28.

Narisada, K.Saito, T. Karasawa, Y. 1977. Perception and road lighting design. Proceedings of SANCI, Durban, 83-86. 
Ikeda, Y. et al. EFFECTIVE LIGHTING FACTORS FOR IMPROVING VISIBILITY OF FALLEN OBJECTS ON THE

\section{Acknowledgment}

This work was supported by JSPS KAKENHI Grant Number 18K13959.

This work was supported by West Nippon Expressway Engineering Shikoku Company Limited. 